\title{
Rationalised prescribing for community acquired pneumonia: a closed loop audit
}

Helena Clements, Terence Stephenson, Vanessa Gabriel, Timothy Harrison, Michael Millar, Alan Smyth, William Tong, Chris J Linton

\begin{abstract}
Aims-To audit the management of community acquired pneumonia before and after the introduction of a protocol. To determine the aetiology of pneumonia using routine investigations and polymerase chain reaction (PCR).

Methods-Retrospective and prospective audit following the introduction of a management protocol. Prospective cases were investigated routinely and with PCR on blood and nasopharyngeal aspirate.

Results-There was a significant increase in rational prescribing following introduction of the protocol with $75 \%$ of children receiving intravenous penicillin or erythromycin compared with $26 \%$ beforehand. Of 89 children in the prospective group, 51 microbiological diagnoses were achieved in 48 children. Seven children had Streptococcus pneumoniae infection, $14 \mathrm{had}$ Mycoplasma infection, six had pertussis, and one had Chlamydia pneumoniae infection. Twenty three children had a viral cause of which respiratory syncytial virus was commonest.

Conclusions-Introduction of the protocol led to improved prescribing. PCR increased the diagnostic yield and the results support the management protocol. (Arch Dis Child 2000;83:320-324)
\end{abstract}

Keywords: community acquired pneumonia; polymerase chain reaction; antibiotics; rationalised prescribing

There is increasing concern about the problem of antimicrobial resistance ${ }^{1}$ which is related to the amount of antibiotics used. ${ }^{23}$ Guidelines for treatment schedules are recommended ${ }^{4}$ and should be based on results derived from well designed surveillance studies. ${ }^{2}$ However, if antibiotics must be given empirically, it is preferable that effective narrow spectrum agents are used whenever possible.

Previous reports of the aetiology of community acquired pneumonia have shown that the main bacterial pathogens are Streptococcus pneumoniae (pneumococcus) and Mycoplasma pneumoniae, ${ }^{5-9}$ but in many cases no pathogen is identified using routine laboratory investigations. We hypothesised that broad spectrum agents continue to be used frequently and inappropriately in childhood pneumonia. Furthermore, we suspected that the low diagnostic yield from conventional investigations contributed to the uncertainty about which antibiotic to prescribe.
Only a small proportion of bacterial pneumonias produce a bacteraemia, ${ }^{10}$ and many children receive antibiotics before presenting to hospital. Therefore, blood cultures are often negative. Direct samples can be obtained by lung puncture or bronchiolar lavage, ${ }^{11}$ but this is too invasive to be done routinely. Young children are unable to produce sputum reliably. Antigen detection in serum and urine has been tried in several studies but results have been conflicting with low sensitivities and specificities. $^{512} 13$ Serology can support a definitive diagnosis but paired titres need to be taken resulting in delay. There are over 80 strains of pneumococci and several subtypes of Haemophilus species, making antibody testing more complex. ${ }^{6}{ }^{14}$

The development of polymerase chain reaction to amplify deoxyribonucleic acid from microorganisms offers the possibility of a rapid bacteriological diagnosis for clinicians. The technique can be used on blood or respiratory secretions and because even small amounts of bacterial deoxyribonucleic acid can be amplified it may be more sensitive than bacterial culture, ${ }^{10}{ }^{14-16}$ particularly if antibiotics have already been given

The purpose of this research was twofold. Firstly, a retrospective study was performed to determine antibiotic prescribing patterns and the rate of detection of pathogens using routine investigations in community acquired pneumonia in children admitted to hospital. Secondly, a prospective study was performed to determine if prescribing could be rationalised without treatment failure following the introduction of a management protocol, and whether diagnosis could be improved by newer molecular biological techniques. This combined approach constituted a closed loop audit to show whether clinical practice could be changed by the introduction of a protocol.

\section{Methods}

DEFINITION

Pneumonia, for the purposes of both the initial retrospective study and the subsequent prospective study, was defined as a respiratory illness with pyrexia, absence of wheeze, and radiological changes on the chest $x$ ray. If the admitting paediatrician identified radiological abnormalities but these were not confirmed by one of two paediatric radiologists at formal reporting, the case was rejected. Wheezy children were excluded as most of these would have been viral induced wheeze and the large numbers would have swamped the smaller number of treatable bacterial pneumonias and 
made the study impossible logistically. Children with chronic disease or those who had been admitted in the previous 10 days were excluded.

\section{RETROSPECTIVE STUDY}

Children (less than 16 years old but excluding infants less than 1 month old) admitted to University Hospital, Nottingham with community acquired pneumonia between 1 September 1994 and 31 August 1995 were identified retrospectively using International Classification of Disease codes. All 27 ICD 10 codes which could include cases of pneumonia were selected and the electronic database of the hospital Patient Administration System was searched for inpatient episodes with the corresponding codes. The case notes from this initial sample were then hand searched to confirm that our inclusion criteria were met. The type of investigations, number of positive microbiological diagnoses, and antibiotic usage before and during admission were recorded.

Following this retrospective study a protocol was designed to standardise the use of microbiological investigations. The protocol also provided guidelines for antibiotic use based on current knowledge of likely pathogens and their sensitivities. Benzylpenicillin was suggested as first line intravenous treatment, with erythromycin for children allergic to penicillin. Phenoxymethylpenicillin (penicillin V) or erythromycin was recommended orally. If a child failed to respond to benzylpenicillin within 48 hours, cefotaxime was suggested as second line therapy by our clinical colleagues who wished to cover the possibility of rarer infections. Similarly, in children under 6 months, cefotaxime was suggested as first line treatment. Ampicillin was recommended for children with pneumonia and sickle cell disease who were already taking penicillin prophylaxis. This was the view of our colleagues on the assumption that if the pathogen is bacterial, it may be penicillin resistant.

PROSPECTIVE STUDY

The prospective study identified all previously well children presenting to University Hospital, Nottingham with the clinical and radiological features of pneumonia during a period of one year (1 October 1996 to 30 September 1997). Informed consent was obtained from their parents and ethical approval for the study was obtained from the local ethics committee.

Children recruited to the study were investigated according to the protocol for the management of pneumonia agreed by the hospital paediatricians (see above). Routine investigations were full blood count, $\mathrm{C}$ reactive protein, blood culture and acute serological titres for common respiratory viruses (influenza A, influenza $\mathrm{B}$, para-influenza, respiratory syncytial virus, adenovirus), Mycoplasma pneumoniae, Chlamydia species, and Legionella species. A nasopharyngeal aspirate or throat swab was obtained for direct immunofluorescence of the respiratory pathogens listed above and bacterial and viral culture. In addition to these routine microbiological investigations, an extra
$2 \mathrm{ml}$ whole blood was frozen and analysed in batches using Pneumolysin, Mycoplasma, and Chlamydia polymerase chain reaction and a portion of the nasopharyngeal aspirate was similarly analysed for Mycoplasma, Chlamydia, and pertussis. ${ }^{17-22}$

Finally, the children were seen two to four weeks later to obtain a further blood specimen for convalescent serology. Prescribing clinicians had access to all the routine investigation results but not to the polymerase chain reaction results as these were analysed subsequently.

\section{Results}

RETROSPECTIVE STUDY

Forty two children between 1 month and 15 years were identified as having been admitted with community acquired pneumonia in the 12 month period using International Classification of Disease codes. Blood culture was taken in 32 with only one positive culture (Streptococcus pneumoniae). Acute serology was obtained in 12 with a raised titre for Mycoplasma in two and adenovirus in three. However, no convalescent titres were measured. A nasopharyngeal aspirate was taken in seven, with respiratory syncytial virus identified in three. The diagnostic rate of presumed pathogens was therefore 9/42 $(21 \%)$

A wide selection of antibiotics was used by both general practitioners and hospital doctors. Twenty children had received an antibiotic before admission, most commonly amoxycillin $(n=9)$ or erythromycin $(n=5)$. Oral penicillin was prescribed in only one case. Following admission, 32 of the 42 children received intravenous antibiotics (table 1). Six children received more than one intravenous antibiotic. Forty of 42 of the children were treated subsequently with an oral antibiotic (table 2). Two children received more than one oral antibiotic.

Table 1 Comparison of intravenous antibiotic use before and after introduction of protocol for management of community acquired pneumonia in hospital

\begin{tabular}{|c|c|c|}
\hline & $\begin{array}{l}\text { Retrospective study } \\
1994-1995(\%)\end{array}$ & $\begin{array}{l}\text { Prospective studyt } \\
1996-1997(\%)\end{array}$ \\
\hline Benzylpenicillin & $10(23.8)$ & $61(68.5)$ \\
\hline Erythromycin & $1(2.3)$ & $6(6.7)$ \\
\hline Cefotaxime & $15(37.5)$ & $13(14.6)$ \\
\hline Ampicillin & $9(21.4)$ & $3(3.4)$ \\
\hline Flucloxacillin & $3(6.9)$ & $2(2.2)$ \\
\hline Metronidazole & $0(0)$ & $2(2.2)$ \\
\hline \multirow{2}{*}{\multicolumn{3}{|c|}{$\begin{array}{l}\text { ^32 of } 42 \text { received one or more intravenous antiobiotics. } \\
\text { †3 of } 89 \text { received one or more intravenous antibiotics. } \\
\text { Table } 2 \text { Comparison of oral antibiotic use after admission } \\
\text { before and after introduction of protocol for management of } \\
\text { community acquired pneumonia in hospital }\end{array}$}} \\
\hline & & \\
\hline & $\begin{array}{l}\text { Retrospective study } \\
1994-1995(\%)\end{array}$ & $\begin{array}{l}\text { Prospective studyt } \\
1996-1997(\%)\end{array}$ \\
\hline Penicillin V & $6(14.3)$ & $43(48)$ \\
\hline Erythromycin & $11(26.2)$ & $16(17)$ \\
\hline Amoxycillin & $15(37.5)$ & $18(20.2)$ \\
\hline Cephradine & $1(2.3)$ & $0(0)$ \\
\hline Co-amoxyclav & $8(19)$ & $4(4.5)$ \\
\hline Metronidazole & $0(0)$ & $2(2.2)$ \\
\hline Clarithromicin & $1(2.3)$ & $0(0)$ \\
\hline
\end{tabular}

$\star 40$ of 42 received one or more oral antibiotics. +78 of 89 received one or more oral antibiotics. 
Table 3 Source of microbiological diagnosis in the prospective study of cases of community acquired pneumonia admitted to hospital

\begin{tabular}{|c|c|c|c|c|c|c|}
\hline & $n$ & $\begin{array}{l}\text { Blood } \\
\text { culture }\end{array}$ & Serology & $\begin{array}{l}\text { Nasopharyngeal } \\
\text { aspirate }\end{array}$ & $\begin{array}{l}\text { Polymerase } \\
\text { chain } \\
\text { reaction } \\
\text { (blood) }\end{array}$ & $\begin{array}{l}\text { Polymerase } \\
\text { chain reaction } \\
\text { (nasopharyngeal } \\
\text { aspirate) }\end{array}$ \\
\hline Streptococcus pneumoniae & 7 & 2 & & & 7 & \\
\hline Mycoplasma & 14 & & 9 & & 6 & 2 \\
\hline Pertussis & 6 & & & & & 6 \\
\hline Chlamydia pneumoniae & 1 & & 1 & 1 & & 1 \\
\hline Viruses & 23 & & 11 & 14 & & \\
\hline
\end{tabular}

Table 4 Age and inflammatory markers in the prospective study of cases of community acquired pneumonia admitted to hospital

\begin{tabular}{|c|c|c|c|c|c|}
\hline & $n$ & $\begin{array}{l}\text { Median } \\
\text { age }\end{array}$ & $\begin{array}{l}\text { Mean total white } \\
\text { cell count } \times 10^{9} / l \\
(95 \% \mathrm{CI})\end{array}$ & $\begin{array}{l}\text { Mean neutrophil } \\
\text { count } \times 10^{9} / l \\
(95 \% C I)\end{array}$ & $\begin{array}{l}\text { Mean } C \text { reactive } \\
\text { protein }(m g / l) \\
\text { (range) }\end{array}$ \\
\hline Streptococcus pneumoniae & 7 & $1 \mathrm{y} 3 \mathrm{~m}$ & $21.8(11.7)$ & $12.2(9.2)$ & $145.8(6-302)$ \\
\hline Mycoplasma & 14 & $3 \mathrm{y} 11 \mathrm{~m}$ & $17.1(5.5)$ & $12.7(5.7)$ & $92.1(6-266)$ \\
\hline Pertussis & 6 & $7 \mathrm{~m}$ & $11.2(1.7)$ & $6.6(2.5)$ & $81.5(6-232)$ \\
\hline Chlamydia pneumoniae & 1 & $2 \mathrm{y} 9 \mathrm{~m}$ & 13 & 11.4 & 8 \\
\hline Viruses & 23 & $1 \mathrm{y} 8 \mathrm{~m}$ & $13.9(3.7)$ & $8.4(5.7)$ & $70.7(6-243)$ \\
\hline No diagnosis & 41 & $3 y 5 \mathrm{~m}$ & $17.5(2.9)$ & - & $118.1(6-376)$ \\
\hline
\end{tabular}

PROSPECTIVE STUDY

Eighty nine children ( 2 months to 15 years 2 months) were recruited during the 12 month period. A microbiological diagnosis was made in 48 children $(54 \%)$, three of whom had dual infections. Streptococcus pneumoniae was identified in seven children, Mycoplasma in 14, pertussis infection in six, and Chlamydia pneumoniae in one child. Twenty three children had viral infections of which 12 were caused by respiratory syncytial virus. Three children were found to have dual infections, two of them with evidence of both Mycoplasma and adenovirus and one with pneumococcus and adenovirus.

Table 3 shows the method of diagnosis for the pneumonias identified. The use of polymerase chain reaction increased the rate of diagnosis of treatable pneumonias from $13 \%$ to $31 \%$. Table 4 shows the clinical characteristics of the children and table 5 the radiographic findings. "Alveolar consolidation" describes radiographic changes in lung parenchyma but not confined to a lobar distribution. "Nonalveolar changes" includes all other radiographic abnormalities consistent with acute infection, most commonly altered bronchovascular markings but also including pleural effusion, hilar changes, etc.

Six children had nasopharyngeal carriage of Haemophilus influenzae, three had nasopharyngeal Streptococcus pneumoniae, and three had Moraxella catarrhalis. Nasal carriage of these organisms did not correspond with the aetiologies identified through other investigations in those children.

Table 5 Radiological findings in the prospective study of cases of community acquired pneumonia admitted to hospital

\begin{tabular}{lrll}
\hline & $\begin{array}{l}\text { Lobar } \\
\text { consolidation }\end{array}$ & $\begin{array}{l}\text { Alveolar } \\
\text { consolidation }\end{array}$ & $\begin{array}{l}\text { Non-alveolar } \\
\text { changes }\end{array}$ \\
\hline Streptococcus pneumoniae & 2 & 3 & 2 \\
Mycoplasma & 11 & 0 & 3 \\
Pertussis & 3 & 1 & 2 \\
Chlamydia pneumoniae & 1 & 0 & 0 \\
Viruses & 14 & 6 & 3 \\
No diagnosis & 29 & 8 & 4 \\
\hline
\end{tabular}

The protocol provided guidelines for antibiotic usage but no direct attempt was made by the researchers to influence individual prescribing. Tables 1 and 2 show that broad spectrum antibiotics were used much less frequently following introduction of the antibiotic guidelines. Twenty six of the children in the prospective study had received an antibiotic before admission. Following admission, 73 of the 89 children received intravenous antibiotics (table 1). Sixty received only one intravenous antibiotic. Of these, 51 received benzylpenicillin alone, eight received cefotaxime alone (five because they were less than 6 months old, one because of suspected penicillin allergy, and two because of the clinician's preference), and one received erythromycin (suspected Mycoplasma on clinical grounds). Twelve children received two different intravenous antibiotics. Causes were: prescription error $(n=1)$; travel abroad $(\mathrm{n}=1)$; clinician preference $(\mathrm{n}=1)$; aspiration $(n=2)$; sickle cell disease $(n=2)$; subsequent clinical suspicion of Mycoplasma ( $n=3)$; and admitted to intensive care from the ward after deteriorating while inpatients $(n=2)$. Of these latter two children, one had pertussis and in the other no microbiological diagnosis was made. One child received three intravenous antibiotics because an empyema developed (Gram positive cocci on microscopy but negative culture). No child was ventilated or died.

Seventy eight of 89 children were treated with an oral antibiotic (table 2). Of these, 39 received penicillin $\mathrm{V}$ alone; 18 received amoxycillin only and four co-amoxiclav only because of clinician preference; and 13 received erythromycin alone because of suspected Mycoplasma. Four children received more than one oral antibiotic. In two, erythromycin was added because of suspicion of Mycoplasma; two children with aspiration had penicillin and metronidazole. Eleven of the 89 children received no oral antibiotics during the admission because a diagnosis of viral pneumonia was made, usually based on nasopharyngeal aspirate results.

\section{Discussion}

The retrospective study showed the frequent use of broad spectrum antibiotics by both general practitioners and hospital paediatricians and the variability in prescribing habits. Routine investigation in hospital was often inconsistent and had a very low diagnostic yield.

In the prospective study, a pathogen was found in $54 \%$ of children. The use of polymerase chain reaction increased the diagnostic rate from $13 \%$ to $31 \%$ for treatable causes of pneumonia. Clinical availability of polymerase chain reaction could provide a rapid diagnosis and aid rational prescribing ${ }^{14}$ and probes are available which can detect resistant organisms. $^{23} 17$ The main disadvantage with polymerase chain reaction is its cost.

Our study has shown that pneumococcus and Mycoplasma are the main bacterial causes of pneumonia and proven dual bacterial and viral infections were not as common as expected. ${ }^{24}$ The idea of typical (pneumococcal) and atypical (Mycoplasma) pneumonias has 
not been upheld. Both diagnoses may present with lobar or interstitial features on chest $x$ ray although a very high white cell count and C reactive protein is more suggestive of pneumococcal pneumonia. However, table 4 shows that the total white cell and neutrophil counts for different aetiologies overlap so much that confident prediction of the microbiological cause of the pneumonia is not possible.

The finding of pertussis in the nasopharyngeal aspirate of six infants was also surprising as there had been no clinical features of pertussis in five of the infants. The highest lymphocyte count was only modestly raised at $6.7 \times 10^{9} / 1$. Three had received an incomplete immunisation course. We are not aware of any convincing study that shows that pertussis or Legionella species occur as "false positives" as a result of carriage without the disease, but carriage of Mycoplasma in the throat is increased in healthy individuals during epidemic years. ${ }^{25} 26$ A study in adults showed that $22 \%$ of healthy controls had Chlamydia pneumoniae detected by polymerase chain reaction on pharyngeal specimens. ${ }^{27}$ However, in the context of a child presenting with a clinical diagnosis of pneumonia and in the absence of other pathogens, it seems reasonable to treat with antibiotics Mycoplasma or Chlamydia found on nasopharyngeal aspirate.

The question of the sensitivity of polymerase chain reaction (PCR) is difficult to resolve because the "gold standard" is usually taken as culture proven cases. Since the point of using PCR is to detect extra cases, if the PCR data are compared against culture data in our study, the assays are " $100 \%$ sensitive" using this "gold standard". In reality, we can say that the pnemococcal and pertussis PCRs which we have used are more sensitive than culture as no culture proven cases were missed by PCR but additional cases were detected. The optimum detection limit for PCR to maximise clinical impact is not known, but the smaller the number of bacteria which the assay detects, the greater chance of false positives. The increasing use of quantitative DNA detection methods will obviate some of these problems by allowing cut off points to be determined for the quantity of DNA which is relevant, as is the case currently with serology.

There were no cases of Haemophilus influenzae infection identified by blood culture. Unfortunately there was no PCR probe or enzyme linked immunosorbent assay (ELISA) kit specific for Haemophilus species available to us. As most children recovered following penicillin or erythromycin alone, this suggests that either the Haemophilus species encountered by our patients were sensitive to these antibiotics or that it is not a common pathogen. The majority of Haemophilus pneumonia is nontype $b,{ }^{28}$ but there is no evidence of a significant increase in non-type b Haemophilus influenzae infection $^{29}$ since the introduction of universal immunisation against type b Haemophilus.

There is a great deal of variability in the antibiotic treatment of pneumonia within and between countries. ${ }^{30}$ In Britain, Davey and colleagues $^{31}$ have shown a significant increase in antibiotic prescribing, in particular broad spectrum antibiotics. A recent survey by the Central Public Health Laboratory Service suggests that penicillin resistant strains are still uncommon in the UK. ${ }^{32}{ }^{33}$ Of the 68 children over 6 months of age who received intravenous antibiotics, $55(81 \%)$ recovered following benzylpenicillin and/or erythromycin. In 10 there were reasons for giving broader spectrum antibiotics. The data support our policy of narrow spectrum antibiotics for community acquired pneumonia. As first line therapy we recommend intravenous benzylpenicillin or an oral penicillin or macrolide, reserving broad spectrum agents for the rare treatment failures and possibly infants under six months of age. As we detected more Mycoplasma than pneumococci, a case could be made for penicillin and a macrolide as the first line therapy. ${ }^{34}$ An important aspect of audit is to confirm that the recommended changes in management are absorbed into routine practice. We have shown that hospital doctors can be influenced to prescribe more rationally. ${ }^{35-37}$

\section{CONCLUSIONS}

This two stage closed loop audit has shown that, at baseline, hospital staff were prescribing a wide range of antibiotics and detection of pathogens was low. The use of a management guideline showed that it is possible to improve the prescribing habits of hospital doctors, with $75 \%$ of children receiving intravenous penicillin or erythromycin compared with only $26 \%$ before the guideline was introduced. This reduces drug costs and, theoretically, should reduce the likelihood of resistant organisms developing to valuable, newer broad spectrum antibiotics. The additional microbiological data provided by PCR support our policy of penicillin and/or a macrolide as initial treatment of community acquired pneumonia as the commonest bacterial pathogens were pneumococci, Mycoplasma, and pertussis. Our data show that the development of rapid detection, "bedside" PCR kits would further aid rational prescribing for pneumonia.

We wish to acknowledge Mr Michael Hawkins, Senior Medical Laboratory Scientific Officer, Department of Microbiology, Nottingham University Hospital; Dr Nigel Broderick and Dr John Somers, Consultant Paediatric Radiologists, University and City Hospitals, Nottingham; and Farida Hussain, Specialist Paediatric Registrar, City Hospital, Nottingham. Hoechst Marion Roussel funded the costs of consumables for the laboratory assays.

1 Wise R, Hart T, Cars O, Streulens M, Helmuth R, Huovinen $\mathrm{P}$, Sprenger $M$. Antimicrobial resistance. BMf P, Sprenger $M$

2 Goosens H, Sprenger JW. Community acquired infections and bacterial resistance. $B M F$ 1998;317:654-7.

3 Hawkey PM. The origins and molecular basis of antibiotic resistance. BMF 1998;317:657-60.

4 Carbon C, Bax RP. Regulating the use of antibiotics in the community. BMF 1998;317:663-5.

5 Isaacs D. Problems in determining the etiology of community acquired pneumonia. Pediatr Infect Dis F 1989;8:143-8.

6 Korpi M, Heiskanen-Kosma T, Jalonen E, et al. Aetiology of community acquired pneumonia in children treated in hospital. Eur f Pediatr 1993;152:24-30.

7 Claesson B, Trollfors B, Brolin I, Granstrom M, Henrichsen J, Jodal U. Etiology of community acquired pneumonia in children based on antibody response to bacterial and viral antigens. Pediatr Infect Dis $\mathcal{F}$ 1989;8:856-62.

8 Nohynek H, Eskola J, Laine E, et al. The causes of hospital treated acute lower respiratory tract infection in children. Am $\mathcal{F}$ Dis Control 1991;145:618-22. 
9 Clyde WA. Clinical overview of typical Mycoplasma pneumoniae infections. Clin Infect Dis 1993;17(suppl pneumoni 1 : $32-6$.

10 Salo P, Ortqvist A, Leinonen M. Diagnosis of bacteremic pneumococcal pneumonia by amplification of pneumolysin gene fragment in serum. F Infect Dis 1995;171:479-82.

11 Silverman M, Stratton D, Diallo A, Egler LJ. Diagnosis of acute bacterial pneumonia in Nigerian children. Arch Dis Child 1977;52:925-31

12 Rusconi F, Rancilio L, Assael B, Cerri M. Counterimmunoelectrophoresis and latex particle agglutination in the etiologic diagnosis of presumed bacterial pneumonia in paediatric patients. Pediatr Infect Dis $\mathcal{F}$ 1988;7:781-5.

13 O’Neill K, Lloyd-Evans N, Campbell H, Forgie I, Sabally S, Greenwood B. Latex agglutination test for diagnosing pneumococcal pneumonia in children in developing countries. BMF 1989;298:1061-4.

14 Rudolph KM, Parkinson AJ, Black CM, Mayer LW. Evaluation of polymerase chain reaction for diagnosis of pneumotion of polymerase chain reaction for diagnosis of pne

15 Gaydos CA, Eiden JJ, Oldach D, et al. Diagnosis of Chlamydia pneumoniae infection in patients with community acquired pneumonia by polymerase chain reaction enzyme

16 Schluger NW, Rom WN. The polymerase chain reaction in the diagnosis and evaluation of pulmonary infections. $A m \mathcal{F}$ Respir Crit Care 1995;152:11-16.

17 Jalal H, Organjii S, Reynolds J, Smart A, Bennett D, O'Mason, Millar MR. Identification of penicillin susceptibility in Streptococcus pneumoniae using the polymerase chain reaction. F Clin Pathol 1997;50:45-50.

18 Tong CYW, Donnelly C, Harvey G, Sillis M. Mutiplex polymerase chain reaction for the simultaneous detection of Mycoplasma pneumoniae, Chlamydia pneumoniae and Chlamydia psittaci in respiratory samples. $\mathcal{F}$ Clin Pathol 1999;52:257-63.

19 Tong CYW, Sillis M. Detection of Chlamydia pneumoniae and Chlamydia psittaci in sputum samples by PCR. 7 Clin Pathol 1993;46:313-17.

20 Cadieux N, Lebel P, Brousseau R. Use of a triplex polymerase chain reaction for the detection and differentiation of Mycoplasma pneumoniae and Mycoplasma genitalium in Mycoplasma pneumoniae and Mycoplasma genitalium in the pres $2431-7$.

21 Mastrantonio P, Stefanelli P, Giuliano M. Polymerase chain reaction for the detection of Bordetella pertussis in clinical nasopharyngeal aspirates. $\mathcal{F}$ Med Microbiol 1996;44:261-6.

22 Kaltenboeck B, Kousoulas KG, Storz J. Two-step polymerase chain reaction and restriction endonuclease analyses detect and differentiate ompA DNA of Chlamydia species. f Clin Microbiol 1992;30:1098-104.

23 Ubukata K, Asahi Y, Yamane A, Konno M. Combination of autolysin and penicillin-binding protein $2 \mathrm{~B}$ genes of Strep- tococcus pneumoniae by polymerase chain reaction. $\mathcal{f}$ Clin Microbiol 1996;34:592-6.

24 Hietala J, Uhari M, Tuokko H, Leinonen M. Mixed bacterial and viral infections are common in children. Pediatr Infect Dis f 1989;8:683-6.

25 Gnarpe J, Lundback A, Sundelof B, Gnarpe H. Prevalence of Mycoplasma pneumoniae in subjectively healthy individuals. Scand 7 Infect Dis 1992;24:161-4.

26 Foy HM. Infections caused by Mycoplasma pneumoniae and possible carrier state in different populations of patients. Clin Infect Dis 1993;17:S37-46.

27 Gabriel AS, Gnarpe H, Gnarpe J, Hallander H, Nyquist O, Martinsson A. The prevalence of chronic Chlamydia pneumoniae infection as detected by polymerase chain reaction in pharyngeal samples from patients with ischaemic heart disease. Eur Heart f 1998;19:1321-7.

28 British Paediatric Surveillance Unit. 12th Annual Report, 1997-1998. London: Royal College of Paediatrics and Child Health, 1998.

29 Hargreaves R, Slack M, Anderson E, Ramsay M, Howard A. Changing patterns of invasive Haemophilus influenzae disease in England and Wales after introduction of the Hib vaccination programme. BMF 1996;312:160-1.

30 Ortqvist A. Antibiotic treatment of community acquired pneumonia in clinical practice: a European perspective. $\mathcal{F}$ Antimicrob Chemother 1995;35:205-12.

31 Davey P, Bax R, Newey J, et al. Growth in the use of antibiotics in the community in England and Scotland in 19801993. BMF 1996;312:613.

32 Johnson AP, Speller DCE, George RC, Warner M, Gil D. Prevalence of antibiotic resistance and serotypes in pneumococci in England and Wales: results of observational surveys in 1990 and 1995. BM7 1996;312:1454-6.

33 George R, Johnson AP, Speller DCE, Efstratiou A, Broughton K, Patel BC. Serogroups/types and antibiotic resistant of referred isolates of Streptococcus pneumoniae 1993-1995. Commun Dis Rep 1997;7:R159-64.

34 Anderson G, Esmonde TS, Coles S, Macklin J, Carnegie C. A comparative safety and efficacy study of clarithromycin and erythromycin stearate in community acquired pneumonia. F Antimicrob Chemother 1991;27(suppl A):117-24.

35 Select Committee on Science and Technology. Subcommittee 1 (House of Lords). 7 th report (session 1997-8). Resistance to antibiotics and other antimicrobial agents. [KL]81-1. London: The Stationery Office, 1998.

36 Standing Medical Advisory Committee (Department of Health). The path of least resistance. Main report. London: Department of Health, 1998.

37 Anon. Tackling antimicrobial resistance. Drug Ther Bull 999;37:9-16. 